\title{
What You Do for Your Team Comes Back to You: A Cross-Level Investigation of Individual Goal Specification, Team-Goal Clarity, and Individual Performance
}

\author{
Sabine Sonnentag \\ University of Konstanz \\ Judith Volmer \\ University of Erlangen-Nuremberg
}

\begin{abstract}
This article reports findings from a longitudinal field study on multilevel processes in teams and examines the role of individual team-goal specification and team-goal clarity with regard to individual performance. It is hypothesized that individual team-goal specification predicts change in individual performance over time, particularly when team-goal clarity is low. Multisource data gathered in 31 project teams supported the hypotheses. Overall, the findings suggest that team members can improve their individual performance when engaging in teamwork processes that are relevant for the team as a whole.
\end{abstract}

In today's work organizations, employees often work in teams. In teamwork research, it is important to not only look at team-level processes and outcomes (Ilgen, Hollenbeck, Johnson, \& Jundt, 2005; Kozlowski \& Bell, 2003) but also examine individual-level processes and outcomes occurring in a team context (Chen, Kirkman, Kanfer, Allen, \& Rosen, 2007; Chen, Thomas, \& Wallace, 2005; DeShon, Kozlowski, Schmidt, Milner, \& Wiechman, 2004). For example, Chen and Kanfer (2006) suggested that team-level and individual-level processes are intertwined in a complex way and that individual-level processes such as the generation and pursuit of goals predict individual performance within teams. In our study conducted in software design teams (cf. Stempfle \& Badke-Schaub, 2002), we build on one part of this model and examine individual contribution to team-goal specification (i.e., the degree to which an individual generates and emphasizes team goals) as an individual-level predictor of individual performance in teams, and address team-goal clarity (i.e., a team's shared understanding of its goals and objectives; De Dreu, De Vries, Fransson, \& Altink, 2000) as a team-level moderator in the relation between individual team-goal specification and individual performance.

Our study extends prior research on individual goal-related processes within teams (Chen et al., 2005; De Shon et al., 2004) to a field setting, thereby increasing external validity. It in-

Correspondence should be sent to Sabine Sonnentag, Department of Psychology, University of Konstanz, Postbox 42, D-78457 Konstanz, Germany. E-mail: sabine.sonnentag@uni-konstanz.de 
cludes longitudinal multisource data, thereby reducing ambiguity when interpreting study findings.

\section{INDIVIDUAL PERFORMANCE IN TEAMS}

In our study, we focus on individual performance as the core outcome variable. In line with the performance framework suggested by Griffin, Neal, and Parker (2007), we conceptualize individual performance as individual task proficiency, that is, individual behaviors that meet expectations and task requirements of an individual - as opposed to a team's task requirement.

From a wider theoretical perspective, it is important to gain insight into how processes that occur in a team context reflect back onto the individuals working in these teams. More specifically, to arrive at a better understanding of task-accomplishment processes in teams, it is important to include individual-level outcomes because individual-level processes are an important input into team-level processes (llgen et al., 2005). From a more applied perspective, individual performance is an important outcome variable in itself, also when individuals work in teams (cf. Olivera \& Strauss, 2004). In many teamwork settings (e.g., project teams), team members often work individually on specific subtasks and later combine their individual products into a collective outcome. When these individual products are of poor quality, overall team performance will suffer. Although team performance is more than an aggregation of individual performance components, team performance remains poor when individual team members' performance is low.

\section{INDIVIDUAL TEAM-GOAL SPECIFICATION AND INDIVIDUAL PERFORMANCE}

Numerous studies have shown that goal-related processes are of paramount importance for performance (LePine, Piccolo, Jackson, Mathieu, \& Saul, 2008; Locke \& Latham, 1990). Within team contexts, goal-related processes that an individual team member engages in may refer not only to individual goals the team member chooses (and pursues) for himself or herself (Wegge \& Haslam, 2005) but also to goals the team member chooses for the team as a whole (Chen et al., 2005; Tasa, Taggar, \& Seijts, 2007). Individual team-goal specification refers to the degree to which an individual team member contributes to the formulation and prioritization of team goals. It is an individual-level activity within a team context that identifies and puts emphasis on team-level goalsas opposed to individual-level goals (Marks, Mathieu, \& Zaccaro, 2001; cf. for similar concepts of goal choice and goal generation, Chen \& Kanfer, 2006). Here, we concentrate on team-goal specification as an individual-level activity by which a team member generates and prioritizes team-level goals.

Within multilevel conceptualizations of teams (Chen \& Kanfer, 2006), individual team-goal specification is a cross-level phenomenon that links individual acts of behavior to the team as the target of this behavior. Individual team-goal specification is a behavior at the individual-level concept (i.e., an individual performs goal-specification activity since it is the individual, not the team as a whole, that specifies the goal) that addresses the team level (i.e., aims at regulating team processes). For example, in a project meeting, a team member suggests and elaborates on a specific goal that the team should prioritize over other goals. This goal-specification activity has the potential to influence the way in which the team approaches and coordinates its subsequent work. Of- 
ten, formal or informal team leaders might be most inclined to specify team goals (Kane, Zaccaro, Tremble, \& Masuda, 2002), but other team members also have ample opportunities to show this activity (Carson, Tesluk, \& Marrone, 2007; Foti \& Hauenstein, 2007).

We propose that the extent to which a team member specifies team goals will be positively related to the team member's individual performance-even if the specified goal is not necessarily adopted by other team members as a team goal. Specifying team goals will help the team member who specifies the goal to arrive at a better mental representation of the team task and to focus on the most important aspects of the task. This will affect the task accomplishment process not only at the team level (O'Leary Kelly, Martocchio, \& Frink, 1994) but also at the individual level, because the individual will put more emphasis on individual goal striving (Chen et al., 2005).

Of course, other team members' individual performance may also benefit from goal specification, but the effect will be most pronounced for the individual who specifies the goal himself or herself. For example, other team members may not pay full attention to the goals discussed or may not completely understand their relevance. In addition - as in a teamwork context, individual team-goal specification implies verbalizing the proposed team goal-the act of verbalizing the team goals and actively reflecting on them will support the individual task completion process (Wetzstein \& Hacker, 2004). Experimental studies have demonstrated that explaining and verbalizing important features of a task and the solution process improves understanding and individual task performance, particularly by increasing meta-cognitive activity (Berardi-Coletta, Buyer, Dominowski, \& Rellinger, 1995; Chi, de Leeuw, Chiu, \& LaVancher, 1994). Goal specification implies such meta-cognitive processes. Moreover, research on collaborative learning has shown that persons who play an active role in the collaborative learning process benefit more from this process than persons who play a more passive role (Slavin, Hurley, \& Chamberlain, 2003). We assume that taking an active role in a collaborative context will pay off not only in a learning setting but also in a task-accomplishment setting.

First empirical support for the assumption that team-goal specification matters for individual performance comes from a study by Chen et al. (2005). Based on data using a flight simulation task performed in two-person teams, the study found that individuals who demonstrated a higher degree of goal choice directed at the team level reported a higher level of goal striving that, in turn, was related to individual performance. We propose the following:

H1: The extent to which a team member specifies team goals will be positively related to this team member's individual task performance.

\section{THE ROLE OF TEAM-GOAL CLARITY}

Chen and Kanfer (2006) argued that in teams, individual performance is not only contingent on individual-level processes but also on team-level processes. We propose that team-goal clarity is particularly important when it comes to goal-related processes and predict that team-goal clarity will moderate the relationship between an individual's team-goal specification and this person's individual task performance. More specifically, we suggest that the relationship will be stronger when team-goal clarity is low rather than when it is high. Generally, goal clarity is defined as the degree to which the objectives of a job are clearly stated and well defined (Sawyer, 1992). In a team context, goal clarity refers to the extent to which members of a team have a shared understanding of the goals and objectives they should pursue as a team (De Dreu et al., 
2000). Teams with clearly defined goals should find it easier to accomplish their tasks because team members can direct and focus their effort on the goal (Anderson \& West, 1998). When discussing individual team-goal specification and team-goal clarity in one joint context, it is important to stress that individual team-goal specification is an individual-level construct referring to the process of suggesting and discussing team goals, whereas team-goal clarity is a team-level construct referring to the shared perception of all team members that team goals are clear and sufficiently specified.

We propose that individual team-goal specification loses its relevance to individual performance in teams where team-goal clarity is high. When team-goal clarity is high, team members know their duties and responsibilities and have an adequate cognitive representation of the goals they should pursue. As a consequence, the need for individual team members to specify team goals is low. Team members can perform well on their individual tasks because they know where to direct their effort. In other words, team-goal clarity can compensate for a lack of individual team-goal specification. When team goal clarity is low, team members' individual actions lack focus and direction. In this case, team members' individual performance will benefit from the activity of team-goal specification. In line with the rationale underlying $\mathrm{H} 1$, we assume that the team member who specifies the team goal will benefit most for his or her individual performance.

Indirect empirical evidence for such an interaction effect of individual team-goal specification level and team-goal clarity comes from an observational study of team meetings (Sonnentag, 2001). Analyses showed that team members who engaged in activities, such as team-goal specification during team meetings, showed higher individual performance than team members who did not engage in these activities only when team meetings lacked a clear structure. Although no causal inferences should be derived from this cross-sectional study, and structure of team meetings does not correspond entirely to team-goal clarity, the findings suggest that individual team-goal specification may be most closely related to individual performance when the team lacks clarity and structure.

H2: Team-goal clarity moderates the relationship between individual team-goal specification and individual performance, with a stronger relationship in teams that have a low level of team-goal clarity.

\section{METHOD}

\section{Overview}

We tested our hypotheses with data from a longitudinal field study in student software design teams. We collected data at two measurement occasions: Time 1 (T1) was 5 weeks after the teams started working together, and Time 2 (T2) was at the end of project work, after teams had worked together for 10 weeks (i.e., 5 weeks after T1). The longitudinal design allowed for a rather strong test of our hypotheses: We predicted individual performance at $\mathrm{T} 2$ from individual goal specification and team-level goal clarity assessed at $\mathrm{T} 1$, by additionally controlling for individual performance at $\mathrm{T} 1$. With this approach, we were able to rule out associations between predictor and outcome variables being accounted for by extemporaneous variables (e.g., cognitive skills). We collected data from multiple sources: the focal participants, their peers, and their tutors. 


\section{Participants}

Data were gathered from computer science students from a large technical university in Germany. Students worked in project teams over the course of one semester. On average, four to six students worked together in a team. The task for these teams was to design a complex software system that could be-in principle-used later in a commercial application. Teams were expected to need the whole semester to complete the task. At the beginning of the semester, the overall team goal ("Please design a software system that meets [technical] requirements") was presented to the team, which left open many options for deciding about specific product features. During the task completion process, team members had numerous opportunities to specify more detailed goals (e.g., "We should try to link module $\mathrm{X}$ directly to module $\mathrm{Y}$ and should define the objects only once"). The team task included typical features of a task in professional software design (e.g., ill-structured, need to collaborate within the team). Because the overall software product included many contingencies and interdependent parts that had to be integrated into the final solution, team members were highly interdependent when working together over the course of the semester.

Each team was coached by one tutor who supported the team while working on the team task (e.g., by offering background information during weekly meetings, by answering emails) and who provided guidance when problems arose. Each tutor was responsible for several teams. Tutors refrained from directly influencing the team's task performance.

At T1, we sent 444 self-report questionnaires to the participating teams. A total of 346 questionnaires from 74 teams were returned. The responses from these 346 persons were used to compute the team-goal clarity measure. However, because 19 participants did not indicate their individual code numbers, questionnaires from these persons could not be matched with peer and tutor data, leaving 327 questionnaires for further consideration (effective response rate $=73.6 \%$ ). Peer data on individual team-goal specification were available for 271 participants out of these 327 , and tutor data on each student's individual performance were available for 312 participants (overlapping sample, $N=264$ ). At T2, 154 students from 39 teams returned the questionnaires $(47.0 \%$ from the 327 students who participated at T1). Because tutor ratings were available for only 142 of the participants and because peer ratings from $\mathrm{T} 1$ were missing for some of the participants, the final sample size was reduced to 123 students working in 31 teams.

The mean age of the participants in the final sample ( $87 \%$ male) was 22.3 years $(S D=2.3)$. The majority of the participants $(83.7 \%$ ) were at the end of the 2 nd year of their studies. About half of the sample had gained experience in professional software design projects, for example, as an intern or a working student. Among those who had experience, average experience was 7.40 months $(S D=12.14)$.

Dropout analysis showed that participants at $\mathrm{T} 2$ did not differ from nonparticipants with respect to demographic variables (gender, age, semester, experience in professional software development) and most other study variables such as individual team-goal specification $(M=3.34, S D$ $=0.50$ for participants; $M=3.36, S D=0.56$ for nonparticipants), $t(261)=0.415, n s$. There were also no differences with respect to team-goal clarity, neither for individual perceptions ( $M=3.64$, $S D=0.50$ for participants; $M=3.68, S D=0.56$ for non;participants), $t(261)=0.405, n s$, nor for data aggregated at the team level $(M=3.66, S D=0.30$ for participants; $M=3.66, S D=0.34$ for nonparticipants), $t(261)=-0.208, n s$. However, participants who remained in the sample at $\mathrm{T} 2 \mathrm{had}$ received higher performance ratings from their tutors at $\mathrm{T} 1(M=5.87, S D=0.97)$ than $\mathrm{T} 1$ participants who did not participate at T2 $(M=5.41, S D=1.00), t(262)=-3.789, p<.001$. 


\section{Measures}

To avoid problems associated with common method and self-serving bias, we collected data from three sources: from the participants themselves (team-goal clarity, control variables), from the participants' peers (individual team-goal specification), and from the participants' tutors (individual performance). Table 1 shows the means, standard deviations, and zero-order correlations for these variables.

\section{Individual Team-Goal Specification}

Individual team-goal specification was measured at $\mathrm{T} 1$ with assessments provided by peers. Specifically, participants were asked to hand a brief questionnaire to three of their peers (fellow team members) with items pertaining to individual team-goal specification. Peers were asked to respond to four team-goal specification items developed by Sonnentag and Volmer (2009). All items referred to goal specification during team meetings, and peers were asked to respond to a 5-point scale, from 1 (not true at all) to 5 (totally true). The items were, "During meetings s/he makes suggestions about which goals we should pursue as a team," "During meetings s/he emphasizes that we reach our goals at a high performance level," "During meetings s/he pleads that we as a team decide on specific goals," "During meetings s/he gets to the heart of what we want to achieve" (Cronbach's $\alpha=.81$ ). On average, ratings from of 2.81 peers were available for each target participant $(S D=0.52)$. Peer agreement on participants' degree of team-goal specification was substantial, ICC $(1)=.348, \eta^{2}=.56, F(122,212)=2.251, p<.001$, with an average deviation index of $A D=0.45$ far below the criterion of $A D=0.80$ suggested as a cutoff value for scales with five response categories (Burke \& Dunlap, 2002). For further analyses, peer assessments of targets' individual team-goal specification were averaged per target participant.

\section{Team-Goal Clarity}

Team-goal clarity was assessed at T1 with six self-report items from a measure developed by Anderson and West (1998). A sample item was, "How clear are you about what your team objectives are?" Cronbach's alpha was .77. We aggregated these individual assessments of team-goal

TABLE 1

Means, Standard Deviations, and Zero-Order Correlations Between Study Variables

\begin{tabular}{|c|c|c|c|c|c|c|c|c|c|}
\hline & $M$ & $S D$ & 1 & 2 & 3 & 4 & 5 & 6 & 7 \\
\hline 1 Gender & 1.87 & 0.34 & & & & & & & \\
\hline 2 Experience & 4.09 & 9.73 & .10 & & & & & & \\
\hline 3 Time size & 5.44 & 1.57 & $-.18 *$ & -.08 & & & & & \\
\hline 4 Other team members' team-goal specification & 3.34 & 0.31 & $-.27 * *$ & $-.15^{*}$ & $-.25 *$ & & & & \\
\hline 5 Individual team-goal specification & 3.34 & 0.50 & -.09 & $.26 * *$ & .08 & $.20 \%$ & & & \\
\hline 6 Team-goal clarity & 3.66 & 0.30 & $-.29 \%$ & .04 & .11 & $.30 * *$ & .18 & & \\
\hline 7 Individual Performance (T1) & 5.87 & 0.98 & -.05 & $.29 *$ & $-.18 *$ & .02 & $.31 * *$ & .16 & \\
\hline 8 Individual Performance (T2) & 6.01 & 1.25 & -.00 & $.28 * *$ & -.09 & -.04 & $.37 * *$ & $.19^{*}$ & $.70 * *$ \\
\hline
\end{tabular}

Note. $N=123$.

$* p<.05 . * *_{p}<.01$. 
clarity to the team level so that the measures used in the analyses reflected all team members' appraisal of team-goal clarity, $\operatorname{ICC}(1)=.538, \eta^{2}=.31, F(30,117)=2.303, p<.01, A D=0.45$ (Burke $\&$ Dunlap, 2002). Note that the sample size here is somewhat larger than for the other analyses because some members for whom no peer or tutor data were available provided ratings of team-goal clarity.

\section{Individual Performance}

Students' tutors provided data on individual performance. Tutors were aware of the specific tasks individual students were responsible for in their teams and had ample opportunities to observe students' performance when consulting with them face-to-face or via e-mail and when supervising their task completion process. Tutors rated each student's performance at $\mathrm{T} 1$ (control variable) and at T2 (outcome variable) by responding to five items developed by Schuler, Funke, Moser, and Donat (1995) for assessing job performance in technical fields. Specifically, tutors were instructed to evaluate each student's performance on the following dimensions by comparing this student with an average student. The five items referred to scientific and technical knowledge, innovation, problem solving, theoretical work, and technical service and had to be answered on a 9-point scale ranging from 1 (extremely below average) to 9 (extremely above average). Exploratory factor analysis showed that all five items loaded on one single factor explaining $70.8 \%$ (T1) and $81.4 \%$ (T2) of the variance. Cronbach's alpha were .92 (T1) and .94 (T2).

\section{Control Variables}

As individual-level control variables, we included gender and months of experience in professional software design project (e.g., as an intern or working student). We controlled for gender because performance ratings in sex-typed tasks such as software design might be biased (Heilman \& Haynes, 2005; Thomas-Hunt \& Phillips, 2004). We included professional experience as a control variable because experience might affect goal-specification activities as well as performance. This influence might only unfold over a longer period and might not yet be reflected in the initial performance ratings. In addition, we controlled for team size and the average level of other team members' team-goal specification. By including other team members' team-goal specification we wanted to rule out the relationship between focal participants' team-goal specification and individuals' performance being attributed to an overall high degree of goal specification within the team. We computed this variable by averaging all team members' individual team-goal specification scores, whereby we excluded the score from the focal participant.

\section{RESULTS}

\section{Test of Hypotheses}

In our data set, data from individuals working together in the teams were not independent from one another. For example, one team member might have influenced other team members' goal-specification activities. Therefore, we tested our hypotheses with the hierarchical linear modelling approach (Bryk \& Raudenbush, 1992) specifying a set of nested models. Individual 
team members' data (individual team-goal specification, control variables) were Level-1 data and team-level data (team-goal clarity) were Level-2 data. ${ }^{1}$

We had predicted that individual team-goal specification predicts individual performance over time (H1) and that this relationship is particularly strong in teams with low levels of team-goal clarity $(\mathrm{H} 2)$. Table 2 shows the findings from hierarchical linear modelling for predicting individual performance at T2. Model 1, which included the control variables gender, months of experience, team size, other team members' team-goal specification, and individual performance at $\mathrm{T} 1$, fit the data better than a Null Model with the intercept as the only predictor (difference of $-2 * \log =$ $63.743, d f=5, p<.001)$. Individual performance at $\mathrm{T} 1$ was a strong predictor of individual performance at T2 $(\gamma=0.766, S E=0.091, t=8.418, p<.001)$, indicating that tutors' ratings of individual performance were pretty stable over the 5-week period. All the other control variables were nonsignificant. In Model 2, we entered individual team-goal specification and team-goal clarity into the model. Again, model fit increased (difference of $-2 * \log =16.114, d f=2, p<.001$ ). Individual team-goal specification at T1 was a strong predictor of individual performance at T2 $\gamma=$ $0.595, S E=0.156, t=3.814, p<.001)$, providing support for $\mathrm{H} 1 .^{2}$ Team-goal clarity did not predict individual performance. Finally, in Model 3 we included the interaction term between individual team-goal specification and team-goal clarity into the model. The increase in model fit and the estimate of the interaction term were significant $(\gamma=-1.262, S E=0.549, t=-2.299, p<.05)$. Thus, individual team-goal specification and team-goal clarity interacted in predicting individual performance at $\mathrm{T} 2$.

To get more insight into the pattern of this interaction effect, we followed the approach suggested by Aiken and West (1991) and tested simple slopes in additional hierarchical linear analyses. For individuals in teams with low team-goal clarity ( $1 S D$ below the mean), individual team-goal specification showed a strong positive association with individual performance $(\gamma=$ $1.074, S E=0.242, t=4.438, p<.01$ ). For individuals in teams with high team-goal clarity ( $S D$ above the mean), individual team-goal specification was not related to individual performance $(\gamma=0.311, S E=0.203, t=1.532, n s)$. Figure 1 displays these two simple slopes. It becomes evident that the relationship between individual team-goal specification and individual performance

\footnotetext{
'Because one tutor was often counseling more than one team, one might argue that a tutor's performance ratings were not independent across the set of teams he or she was supervising. To examine if the potential dependence of tutors' ratings influenced our findings, we ran hierarchical linear models with three levels (tutors, teams, individuals) with teams nested in tutors and individuals nested in teams. As predictors, we entered the same variables as in the analyses summarized in Table 2. Analysis showed that variance at the tutor level was very small, both for a null model with the intercept as the only predictor ( $9.18 \%$ of the total variance) and the final model with all predictor variables entered (13.44\% of the total variance). In addition, all significant predictor variables found in the two-level models remained significant when running such a three-level model, with tutors as the third level (for individual team-goal specification, $\gamma=0.633, S E=0.152, t=4.164$, $p<.001$; for the interaction term between individual team-goal specification and team-goal clarity, $\gamma=-1.307, S E=0.551$, $t=2.372, p<.05$ ). These findings imply that possible tutor effects did not play a major role. Thus, we are confident that the fact that tutors rated team members' individual performance in multiple teams did not influence our findings.

${ }^{2}$ One might argue that the relationship between an individual team-goal specification and his or her individual performance does not show a linear, but rather a curvilinear relationship. Such a curvilinear relationship would follow an inversed U-shaped pattern with low levels of individual team-goal specification being associated with low performance, medium levels of individual team-goal specification being associated with high performance, and high levels of individual team-goal specification being, again, associated with low performance. We tested for such a curvilinear relationship by entering the quadratic term of individual team-goal specification. Entering this quadratic term did not improve model fit and the estimate of the term was not significant $(\gamma=-0.093, S E=0.202, t=0.460, n s)$.
} 
TABLE 2

Predicting Individual Performance at Time 2 from Individual Team-Goal Specification and Team-Goal Clarity at Time 1

\begin{tabular}{|c|c|c|c|c|c|c|c|c|c|}
\hline & \multicolumn{3}{|c|}{ Model I } & \multicolumn{3}{|c|}{ Model 2} & \multicolumn{3}{|c|}{ Model 3} \\
\hline & Estimate & $S E$ & $t$ & Estimate & $S E$ & $t$ & Estimate & $S E$ & $t$ \\
\hline Intercept & 6.017 & 0.116 & 51.871 & 6.040 & 0.122 & 49.508 & 6.077 & 0.120 & 50.542 \\
\hline Gender & 0.043 & 0.240 & 0.179 & 0.102 & 0.223 & 0.457 & 0.124 & 0.219 & 0.566 \\
\hline Experience & 0.009 & 0.008 & 1.125 & 0.003 & 0.008 & 0.375 & 0.003 & 0.007 & 0.429 \\
\hline Team size & 0.046 & 0.074 & 0.622 & 0.016 & 0.070 & 0.229 & 0.021 & 0.069 & 0.304 \\
\hline Other team members' team-goal specification & -0.378 & 0.329 & $-1,149$ & -0.317 & 0.347 & -0.914 & -0.299 & 0.337 & -0.887 \\
\hline Performance at Time 1 & 0.766 & 0.091 & $8.418^{* * * *}$ & 0.608 & 0.090 & $6.756^{* * * *}$ & 0.596 & 0.089 & $6.697^{* * *}$ \\
\hline Individual team-goal specification & & & & 0.595 & 0.156 & $3.814^{k * 3}$ & 0.655 & 0.155 & $4.226^{1,2 * k s}$ \\
\hline Team-goal clarity & & & & 0.606 & 0.423 & 1.433 & 0.640 & 0.411 & 1.5558 \\
\hline $\begin{array}{l}\text { Individual Team-Goal Specification } x \\
\text { Team-Goal Clarity }\end{array}$ & & & & & & & -1.262 & 0.549 & $-2.299^{*}$ \\
\hline$-2 * \log (\mathrm{lh})$ & 307.329 & & & 291.215 & & & 286.041 & & \\
\hline Diff $-2 \times \log$ & $63.743^{* \times 2 \times \cdots}$ & & & $16.114^{* * * * *}$ & & & $5.174^{*}$ & & \\
\hline$d f$ & 5 & & & 2 & & & 1 & & \\
\hline Level I Intercept Variance $(S E)$ & $0.551(0.081)$ & . & & $0.447(0.066)$ & & & $0.431(0.063)$ & & \\
\hline Level 2 Intercept Variance $(S E)$ & $0.254(0.103)$ & & & $0.327(0.115)$ & & & $0.305(0.118)$ & & \\
\hline
\end{tabular}

$$
* p<.05 . * *_{p}<.01, * * * p<001 \text {. }
$$


Individual Performance at Time 2

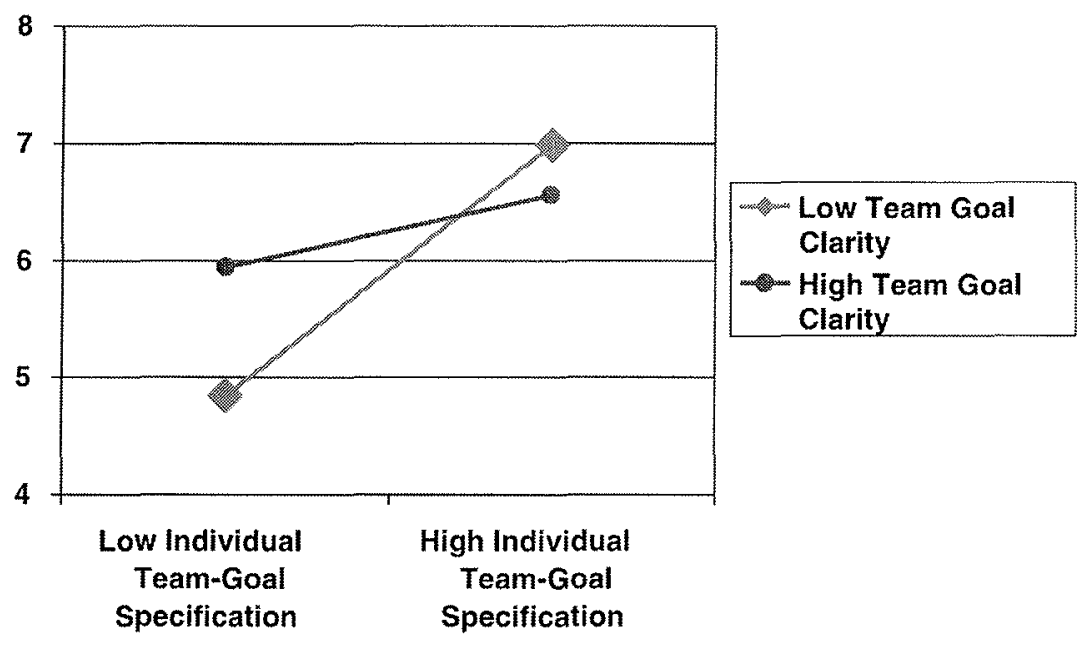

FIGURE 1 Interaction effect between individual team-goal specification and team-goal clarity.

at $\mathrm{T} 2$ was positive in teams with low team-goal clarity, but not in teams with high team-goal clarity. This specific interaction pattern supports $\mathrm{H} 2$.

\section{DISCUSSION}

Kozlowski and Bell (2003) argued that "teams do not think, feel, or behave; individuals do" (p. 363). Individuals in teams, however, do not think, feel, and behave in isolation but in an interactive context. This awareness of individual-level processes in team contexts is reflected in an increasing number of studies examining individual performance and its predictors within team settings (Chen et al., 2007; De Shon et al., 2004). Our study adds to this growing body of research. Using multiple-source data, this study provided evidence that individual team-goal specification during team meetings predicted individual performance. Moreover, this relationship between individual team-goal specification and individual performance was more pronounced in teams with low team-goal clarity. Because we controlled for individual performance at $\mathrm{T} 1$, our findings suggest that the team-goal specification is related to change in performance: Team members increase their individual performance level by specifying team goals, particularly when team-goal clarity is low.

Of importance, individual team-goal specification and the interaction term predicted change in individual performance when controlling for a range of other variables, including other team members' team-goal specification activities. This result implies that it is not the overall level of team-goal specification within a team that accounts for the study findings. Thus, we can rule out that team members' individual performance levels benefit from a high degree of passivity of the other members (in case of low average team-goal specification scores) or from a high level of specified team goals (in case of high average team-goal specification scores). Rather, it seems that 
the fact of actively specifying team goals oneself contributes to the performance increase over time.

Overall, our study showed that paying attention to team goals and influencing them, on one hand, and arriving at high individual performance, on the other hand, are not contradictory and irreconcilable objectives in a teamwork setting (cf. Crown \& Rosse, 1995; DeShon et al., 2004; Mitchell \& Silver, 1990). The first seems to be a means to achieve the latter. However, the benefit of individual team-goal specification is contingent on team characteristics. When team-goal clarity is high, individuals specifying team goals do not invest their cognitive resources in an optimal way because they should already have a good cognitive representation of the team's goals.

Our results mirror cross-sectional findings from a recent study by Chen et al. (2007), who reported that individual-level empowerment was positively related to individual performance, particularly when team-level empowerment was low. The findings from the two studies might suggest that when team members feel competent and are provided with the opportunity to exert influence on the team process (as is the case with empowerment) and when team members in fact use this opportunity (as is the case with team-goal specification), then their individual performance increases. One might speculate that when team members feel empowered by experiencing impact, competence, meaningfulness, and choice (cf. Spreitzer, 1995), they are more likely to specify goals for their teams. In addition, the process of specifying team goals will contribute to the perception of empowerment. Future research might want to integrate the examination of goal specification and empowerment processes in one study.

Moreover, our study illustrates that team characteristics (e.g., low team-goal clarity) that have negative outcomes at the team level (Anderson \& West, 1998) can be associated with benefits at the individual level. When team-goal clarity within a team is low, individual team members' performance gains from individual team-goal specification. Thus, although low team-goal clarity may impede team-level performance, it provides the opportunity for individual team members to take advantage from their individual team-goal specification activity.

\section{Limitations}

Our study has some limitations. First, although the use of multiple-source data largely reduces the chances that our findings suffer from common source bias (Podsakoff, MacKenzie, Lee, \& Podsakoff, 2003), it can not be ruled out completely that tutors' observations of student behavior during project meetings might have influenced the findings to some degree. Because tutors were present in project meetings from time to time, they might have based their assessment of students' performance partly on students' behavior during project meetings. As a consequence, tutors' performance ratings might reflect not only students' performance but also tutors' observations of students' goal-specification behavior during meetings. We assume that the effect of such a potential bias in tutors' performance ratings is not very severe because we controlled for performance ratings at $\mathrm{T} 1$, when the performance measures would have already been biased.

Second, attrition of study participants from $\mathrm{T} 1$ to $\mathrm{T} 2$ was not completely at random, with students who were showing high performance at $\mathrm{T} 1$ were overrepresented in the final sample. At $\mathrm{T} 2$, poor performers might have seen further study participation as an additional burden or might have been reluctant to ask their tutors for a performance assessment. Thus, although our data might indicate that individual team-goal specification increases performance over time, particularly in rel- 
atively well-performing students, our results are noteworthy because we found the proposed relationship despite range restriction in performance measures.

A further limitation refers to the task setting we used. We focussed on software design tasks to be completed in a project setting. Thus, the role of goal specification might be typical for this type of task and this team context. Particularly in action teams (e.g., rescue teams) that need to come up with quick responses to an emergency, extensive elaboration about the goals to be pursued might largely impede performance (Tschan et al., 2006). However, action teams might benefit also from team-goal specification enacted during times in-between their missions (Chen et al., 2005).

Moreover, in our study we concentrated on individual team-goal specification activities during meetings. Although meetings are a prominent setting for teamwork processes, goal-specification activities certainly also occur and are necessary in other settings such as informal day-to-day consultations or in electronically mediated communication. Therefore, future research should examine the effects of individual team-goal specification in other settings.

\section{Implications for Research and Practice}

An important question to be addressed in future research refers to the mediating processes underlying the relationship between individual team-goal specification (and their interaction with team-goal clarity) and individual performance. In the introduction, we argued that individual team-goal specification leads to a better understanding and cognitive representation of the task which, in turn, should improve individual performance. In addition, social-exchange processes might play a role as mediator (Blau, 1964; Cropanzano \& Mitchell, 2005). An individual who specifies team goals might in return receive some kind of support from the other team members. Thus, others might be more inclined to help this team member, provide him or her with information or other resources that will be useful for this person to arrive at a high level of individual performance.

Future studies may also want to include observational or verbal-protocol data and examine the content of the goals that have been specified and that have been later adopted versus dismissed in the team process. Such an approach will provide more information about the features of the goals and the goal-specification activities, which are important for the subsequent actions a team takes.

We focused on team-goal clarity as one specific moderator in the relationship between individual team-goal specification and individual performance. Future research might address other moderators such as task complexity and task novelty. One can assume that in rather simple and routine task settings that do not require a high degree of goal specification, such activities do not play a major role in affecting individual task performance. Similarly, team member experience and task proficiency might function as a moderator. When team members are highly experienced and highly proficient in the task, goal specification might not add anything to individual task performance because team members might already have well-developed mental representations of the goals to be pursued.

Increasingly, team work is performed in dispersed and virtual teams without much direct interaction (Hertel, Geister, \& Konradt, 2005; Hinds \& Bailey, 2003). Thus, it would be an interesting task for future research to apply the concept of individual team-goal specification to the growing number of virtual teams and to examine how individuals can engage in some kind of team-goal specification that might benefit their individual performance when working in a virtual team. 
Our study offers some advice for team management. Because individual team-goal specification results in improved individual performance and because other team members' goal specification does not impede performance, it seems reasonable to train team members in such a teamwork skill (Ellis, Bell, Ployhart, Hollenbeck, \& Ilgen, 2005; Gibson, 2001) and to provide opportunities to practice these skills. This approach is particularly important in areas where team goals are not clearly specified, for instance, in early phases of project work. However, practically speaking, encouraging individual team-goal specification may have limits. Particularly, in a large team there might not be enough time for everyone to express his or her ideas about the team's goals openly in a meeting. Here, discussions in smaller groups might be helpful. Although individual performance reached the highest levels when individual team-goal specification was high and team-goal clarity was low, we do not suggest that team-goal clarity should be reduced deliberately because team-goal clarity is important for team performance (West \& Anderson, 1996).

\section{Conclusion}

Our study has shown that individual performance can benefit from individual team-goal specification during team meetings, particularly when overall team-goal clarity is low. Empirical studies have shown that meetings are often time-consuming and are perceived as a source of stress (Luong \& Rogelberg, 2005; Rogelberg, Leach, Warr, \& Burnfield, 2006). Although we do not deny the potential negative side effects of poorly planned and structured meetings, our study points to one specific opportunity that meetings do offer. Individuals can benefit from specifying team goals during meetings, particularly when overall team-goal clarity is low.

\section{ACKNOWLEDGMENTS}

This research was funded by a grant from the German Research Foundation (DFG; SO 295/3-1, 3-2) that is gratefully acknowledged. We thank the ikoso teams at the Technical University of Braunschweig and the University of Konstanz for their involvement and enthusiasm during data collection. We are grateful to Birgit Demuth for her support when conducting the Study and Carmen Binnewies, Adam M. Grant, Eva J. Mojza, Cornelia Niessen, Sandra Ohly, Anne Spychala, and anonymous reviewers for insightful comments on earlier versions of this article. We thank Anastasia Byler for helping with grammar and spelling issues.

\section{REFERENCES}

Aiken, L. S., \& West, S. G. (1991). Multiple regression: Testing and interpreting interactions. Newbury Park, CA: Sage. Anderson, N. R., \& West, M. A. (1998). Measuring climate for work group innovation: Development and validation of the team climate inventory. Journal of Organizational Behavior, 19, 235-258.

Berardi-Coletta, B., Buyer, L. S., Dominowski, R. L., \& Rellinger, E. R. (1995). Metacognition and problem solving: a process-oriented approach. Joumal of Experimental Psychology: Learning, Memory, and Cognition, 21, 205-223.

Blau, P. M. (1964). Exchange and power in social life. New York: Wiley.

Bryk, A. S., \& Raudenbush, S. W. (1992). Hierarchical linear models: Application and data analysis methods. Newbury Park, CA: Sage.

Burke, M. J., \& Dunlap, W. P. (2002). Estimating interrater agreement with the average deviation index: A user's guide. Organizational Research Methods, 5, 159-172. 
Carson, J. B., Tesluk, P. E., \& Marrone, J. A. (2007). Shared leadership in teams: An investigation of antecedent conditions and performance. Academy of Managentent Journal, 50, 1217-1234.

Chen, G., \& Kanfer, R. (2006). Toward a systems theory of motivated behavior in work teams. Research in Organizational Behavior, 27, 223-267.

Chen, G., Kirkman, B. L., Kanfer, R., Allen, D., \& Rosen, B. (2007). A multilevel study of leadership, empowerment, and performance in teams. Joumal of Applied Psychology, 92, 331-346.

Chen, G., Thomas, B., \& Wallace, J. C. (2005). A multilevel examination of the relationships among training outcomes, mediating regulatory processes, and adaptive performance. Joumal of Applied Psychology, 90, 827-841.

Chi, M. T. H., de Leeuw, N., Chiu, M.-H., \& LaVancher, C. (1994). Eliciting self-explanations improves understanding. Cognitive Science, 18, 439-477.

Cropanzano, R., \& Mitchell, M. S. (2005). Social exchange theory: An interdisciplinary review. Journal of Management, $31,874-900$.

Crown, D. F., \& Rosse, J. G. (1995). Yours, mine, and ours: Facilitating group productivity through the integration of individual and group goals. Organizational Behavior and Human Decision Processes, 64, 138-150.

De Dreu, C. K. W., De Vries, N. K., Fransson, H., \& Altink, W. M. M. (2000). Minority dissent in organizations: Factors influencing willingness to dissent. Journal of Applied Social Psychology, 30, 2451-2466.

DeShon, R. P., Kozlowski, S. W. J., Schmidt, A. M., Milner, K. R., \& Wiechman, D. (2004). A multiple-goal, multilevel model of feedback effects on the regulation of individual and team performance. Joumal of Applied Psychology, 89, $1035-1056$

Ellis, A. P. J., Bell, B. S., Ployhart, R. E., Hollenbeck, J. R., \& Ilgen, D. R. (2005). An evaluation of generic teamwork skills training with action teams: Effects on cognitive and skill-based outcomes. Personnel Psychology, 58, 641-672.

Foti, R. J., \& Hauenstein, N. M. A. (2007). Pattern and variable approaches in leadership emergence and effectiveness. Journal of Applied Psychology, 92, 347-355.

Gibson, C. B. (2001). Me and us: Differential relationships among goal-setting training, efficacy and effectiveness at the individual and team level. Journal of Organizational Behavior, 22, 789-808.

Griffin, M. A., Neal, A., \& Parker, S. K. (2007). A new model of work role performance: Positive behavior in uncertain and interdependent contexts. Academy of Management Journal, 50, 327-347.

Heilman, M. E., \& Haynes, M. C. (2005). No credit where credit is due: Attributional rationalization of women's success in male-female teams. Journal of Applied Psychology, 90, 905-916.

Hertel, G., Geister, S., \& Konradt, U. (2005). Managing virtual teams: A review of current empirical research. Human Re source Management Review, 15, 69-95.

Hinds, P., \& Bailey, D. (2003). Out of sight, out of sync: Understanding conflict in distributed teams. Organization Science, $14,615-632$.

Ilgen, D. R., Hollenbeck, J. R., Johnson, M., \& Jundt, D. (2005). Teams in organizations: From input-process-output models to IMOI models. Annual Review of Psychology, 56, 517-543.

Kane, T. D., Zaccaro, S. J., Tremble, T. R. J., \& Masuda, A. D. (2002). An examination of the leaders' regulation of groups. Small Group Research, 33, 65-120.

Kozlowski, S. W. J., \& Bell, B. S. (2003). Work groups and teams in organizations. In W. C. Borman, D. R. Ilgen, \& R. J. Klimoski (Eds.), Handbook of psychology: Industrial and organizational psychology (Vol. 12, pp. 333-375). Hoboken, NJ: Wiley.

LePine, J. A., Piccolo, R. F., Jackson, C. L., Mathieu, J. E., \& Saul, J. R. (2008). A meta-analysis of teamwork processes: Tests of a multidimensional model and relationships with team effectiveness criteria. Personnel Psychology, 61, 273-307.

Locke, E. A., \& Latham, G. O. (1990). A theory of goal setting and task performance. Englewood Cliffs, NJ: Prentice Hall.

Luong, A., \& Rogelberg, S. G. (2005). Meetings and more meetings: The relationship between meeting load and the daily well-being of employees. Group Dynamics: Theory, Research, and Practice, 9, 58-67.

Marks, M. A., Mathieu, J. E., \& Zaccaro, S. J. (2001). A temporally based framework and taxonomy of team processes. Academy of Management Review, 26, 356-376.

Mitchell, T. R., \& Silver, W. S. (1990). Individual and group goals when workers are interdependent: Effects on task strategies and performance. Journal of Applied Psychology, 75, 185-193.

O'Leary Kelly, A. M., Martocchio, J. J., \& Frink, D. D. (1994). A review of the influence of group goals on group performance. Academy of Management Journal, 37, 1285-1301.

Olivera, F., \& Straus, S. G. (2004). Group-to-individual transfer of learning. Cognitive and social factors. Small Group Research, 35, 440-465. 
Podsakoff, P. M., MacKenzie, S. B., Lee, J.-Y., \& Podsakoff, N. P. (2003). Common method biases in behavioral research: A critical review of the literature and recommended remedies. Journal of Applied Psychology, 88, 879-903.

Rogelberg, S. G., Leach, D. J., Warr, P. B., \& Burnfield, J. L. (2006). "Not another meeting!" Are meeting time demands related to employee well-being. Journal of Applied Psychology, 91, 83-96.

Sawyer, J. E. (1992). Goal and process clarity: Specification of multiple constructs of role ambiguity and a structural equation model of their antecedents and consequences. Journal of Applied Psychology, 77, 130-142.

Schuler, H., Funke, U., Moser, K., \& Donat, M. (1995). Personalauswahl in Forschung und Entwicklung: Eignung und Leistung von Wissenschaftlem und Ingenieuren (Personnel selection in research and development: Aptitude and performance of scientists and engineers]. Göttingen, Germany: Hogrefe.

Slavin, R. E., Hurley, E. A., \& Chamberlain, A. (2003). Cooperative learning and achievement: Theory and research. In W. M. Reynolds \& G. E. Miller (Eds.), Handbook of psychology (Vol. 7; Educational psychology, pp. 177-198). Hoboken, NJ: Wiley.

Sonnentag, S. (2001). High performance and meeting participation. An observational study in software design teams. Group Dynamics: Theory, Research and Practice, 5, 3-18.

Sonnentag, S., \& Volmer, J. (2009). Individual-level predictors of task-related teamwork processes: The role of expertise and self-efficacy in team meetings. Group \& Organization Management, 34, 37-66.

Spreitzer, G. M. (1995). Psychological empowerment in the workplace: Dimensions, measurement, and validation. Academy of Management Journal, 38, 1442-1465.

Stempfle, J., \& Badke-Schaub, P. (2002). Thinking in design teams-An analysis of team communication. Design Studies, $23,473-496$.

Tasa, K., Taggar, S., \& Seijts, G. H. (2007). The development of collective efficacy in teams: A multilevel and longitudinal perspective. Journal of Applied Psychology, 92, 17-27.

Thomas-Hunt, M. C., \& Phillips, K. W. (2004). When what you know is not enough: Expertise and gender dynamics in task groups. Personality and Social Psychology Bulletin, 30, 1585-1598.

Tschan, F., Semmer, N. K., Gautschi, D., Hunziker, P., Spychiger, M., \& Marsch, S. U. (2006). Leading to recovery: Group performance and coordinative activities in medical emergency driven groups. Human Performance, 19, 277-304.

Wegge, J., \& Haslam, S. A. (2005). Improving work motivation and performance in brainstorming groups: The effects of three group goal-setting strategies. European Journal of Work and Organizational Psychology, 14, 400-430.

West, M. A., \& Anderson, N. R. (1996). Innovation in top management teams. Journal of Applied Psychology, 81, $680-693$.

Wetzstein, A., \& Hacker, W. (2004). Reflective verbalization improves solutions-The effects of question-based reflection in design problem solving. Applied Cognitive Psychology, I8, 145-156. 